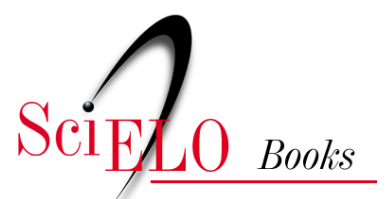

\title{
Capítulo 6 \\ Anos 1990, a descontinuidade ou quando antigos atores saem de cena
}

\author{
Alexis Cortés
}

CORTÉS, A. Anos 1990, a descontinuidade ou quando antigos atores saem de cena. In: Favelados e pobladores nas ciências sociais: a construção teórica de um movimento social [online]. Rio de Janeiro: EDUERJ, 2018, pp. 331-343. Sociedade \& política collection. ISBN: 978-85-7511-477-3. https://doi.org/10.7476/9788575114773.0007.

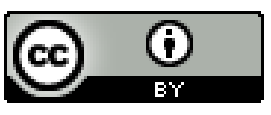

All the contents of this work, except where otherwise noted, is licensed under a Creative Commons Attribution 4.0 $\underline{\text { International license. }}$

Todo o conteúdo deste trabalho, exceto quando houver ressalva, é publicado sob a licença Creative Commons Atribição 4.0.

Todo el contenido de esta obra, excepto donde se indique lo contrario, está bajo licencia de la licencia Creative Commons Reconocimento 4.0. 


\section{Capítulo 6 \\ Anos 1990, A DESCONTINUIDADE OU QUANDO \\ ANTIGOS ATORES SAEM DE CENA}

A década de 1990 marca um clima intelectual bastante diferente das décadas anteriores. Segundo Eduardo Devés (2004b), a questão da "identidade" será o centro do pensamento latino-americano dos anos 1990. Os movimentos sociais, embora não desapareçam como tópico de reflexão das agendas de pesquisa, agora aparecem transmutados como movimentos identitários. Se, por um lado, a resistência identitária frente à globalização será o grande eixo do pensamento continental, por outro, ganham centralidade temáticas, tais como: a democracia, a transição, a sociedade civil, a cidadania, a reforma do Estado, a governabilidade. Conhecidos atores sociais saem de cena e novas prioridades aparecem nas ciências sociais.

Nos anos oitenta e profundizada nos noventa, se produz uma diáspora no pensamento crítico latino-americano. A visão organicista e funcional sobre o caráter dos conflitos e crises societais é assumida como um referente válido. Novamente ordem e progresso. Governabilidade e paz social. Os apelos a manter as reformas neoliberais do Estado, os procesos de privatização, assim como os programas econômicos sobre pactos de exclusão fundamentados no mito do progresso nos fazem pensar na refundação do poder. Uma refundação totalitária e neo-oligárquica, na qual oferecer um projeto alternativo pode ser considerado subversivo e desarticulador do corpo social (ROITMAN ROSENMANN, 2000, p. 170). 


\section{Os pobladores nas margens da transição democrática}

No caso do Chile, o retorno à democracia não significou a abertura de novos canais de participação e de protagonismo para o movimento de pobladores. Com o fim da Ditadura Militar, se estabeleceu um pacto que tinha como condição de estabilidade a paulatina desmobilização das forças sociais que contribuíram para o fim do regime. Com isso, o Movimento de Pobladores praticamente desapareceu da cena política e da agenda de pesquisa de boa parte das ciências sociais, notadamente da sociologia e da ciência política.

Se, depois de realizado o golpe, as ciências sociais se perguntavam amargamente por onde estavam os pobladores radicalizados, de começos dos anos 1970, que tinham concentrado as esperaças de protagonizar uma mudança estrutural e eventualmente resistir às tentativas contra-revolucionárias da burguesia chilena, no início dos anos 1990, alguns pesquisadores reatualizavam o questionamento: aonde foram os pobres urbanos que se mobilizaram durante os anos 1980 contra a ditadura militar (OXHORN, 1994)?

Segundo Manuel Antonio Garretón (1987), apesar de que, com os protestos populares de 1983, a mobilização social tenha chegado a ocupar um lugar central na relação regime-oposição e nas definições estratégicas desta última, elas não foram suficientes para constituir atores sociais autônomos, nem para conseguir satisfazer as expectativas criadas em relação ao seu papel na transição. A "transição invisível", o fenômeno de redemocratização da sociedade via reorganização dos atores sociais, não se traduziu numa "transição formal", pela manifesta incapacidade da mobilização popular de passar à ação política como sujeito coletivo autônomo. No final, a transição ficou em mãos de atores políticos enfrentados aos seus próprios problemas constitutivos. O regime militar não foi capaz de eliminar os atores sociais, mas estes também não foram capazes de derrubá-lo, deixando a transição "invisível" in- 
completa. Com a transição democrática se cumpria a profecia que negava a condição de movimento social aos pobladores?

Já a começos da década de 1990, o historiador Gonzalo Cáceres (1993) advertia sobre a dificuldade de que o "renascido" Movimento de Pobladores dos anos 1980 mantivesse o protagonismo alcançado durante a ditadura. Por um lado, porque as lógicas transicionais que privilegiaram a estabilidade se sustentavam numa baixa pressão setorial, sendo que as instâncias de coordenação metropolitana do movimento de pobladores eram incapazes de manter a convocatória e a unidade de outros momentos; por outro, porque a dinâmica do mercado imobiliário limitava o principal repertório de ação coletiva dos pobladores: a tomada de terrenos. Com a privatização do espaço urbano, escasseavam terrenos potenciais para serem ocupados. Por outra parte, uma vez instalada no governo, a Concertación iniciou uma das políticas habitacionais mais bem sucedidas em termos quantitativos na América Latina. Embora reduzisse significativamente o déficit habitacional, ao mesmo tempo, privilegiava uma solução institucional baseada na poupança familiar, que se apoiou em soluções de baixa qualidade, que descontinuaram as redes sociais dos pobladores, estimularam novas formas de marginalidade (gangues, drogas e violência) e terminaram por constituir bairros degradados (DUCCI, 1997). Em outras palavras, resolveu em grande medida o problema dos "sem teto" para criar um novo problema, desta vez dos "com teto" (RODRÍGUEZ e SUNGRAYES, 2006).

Vicente Espinoza (1993) salientará que este cenário adverso à ação coletiva dos pobladores poderia seduzir os cientistas sociais para um diagnóstico apressado que estabelecesse o definitivo fim do movimento. A descontinuidade da ação coletiva dos pobladores é, para ele, uma constante histórica que, portanto, deve ser considerada na própria definição do ator, assim como se deve considerar a posição do conflito urbano no contexto da ação coletiva, ao invés de reduzir os movimentos sociais à presença/ausência de 
conflitos. O Movimento de Pobladores não é apenas um agregado de mobilizaçôes descontínuas. Para compreendê-lo, é preciso distinguir entre o "tempo curto" (conjunturas de irrupção ou ausência) e o "tempo longo" de caráter histórico. Se o analista fica com o "tempo curto" da conjuntura, tenderá a cair em leituras descontinuistas. Em contraposição, o "tempo longo" permitirá apreciar os elementos de continuidade do movimento social.

É precisamente com esse intuito que Espinoza (1998) retomará alguns dos elementos do seu trabalho de colaboração na equipe dirigida por François Dubet, propondo uma releitura do Movimento de Pobladores a partir de quatro eixos de ação coletiva: ação reivindicativa, participação institucional, ação comunitária e lógica de ruptura. Embora esta caracterização mostre alguns problemas ao misturar tipos ideais com tipos históricos (cada eixo de ação é característica de um período diferente do movimento), será útil para sustentar um ponto vital na concepção deste autor sobre os pobladores: a história dos pobladores indica que a ausência de conflito direto (irrupção) não é sinônimo de desaparição permanente do movimento. Aliás, o grande desafio do movimento com o retorno da democracia é sua integração política. Embora na figura da municipalidad exista um potencial de institucionalização das demandas, a eleição de militantes do movimento no aparelho municipal não resolve a questão, pelos riscos de burocratização implícitos. Porém, Espinoza (1993) não vê necessariamente o fim do Movimento de Pobladores, mas uma nova página na relação entre movimento e Estado, dada pela capacidade deste último de absorver de maneira mais eficiente e mais ampla as demandas dos pobres e pelo melhoramento da capacidade de negociação dos pobladores frente a este Estado mais responsivo. Espinoza (1994) chamará a atenção também para o fato de que grande parte do tecido social popular corresponde a processos microssociais de sobrevivência, introduzindo um novo fator de compreensão dos pobladores: as redes sociais. El pasaje, rua típica das poblaciones chilenas, será o 
espaço territorial privilegiado de compreensão dos processos de adaptação e integração social das famílias populares chilenas para enfrentar os desafios da sobrevivência cotidiana. Se as lideranças do movimento ignoram esse fato, aumentarão as chances de que continue se ampliando a distância com suas próprias bases. A principal tarefa do movimento, nesse sentido, é a passagem desde as ruas da población às "grandes Alamedas".

Ton Salman (1998) utilizará outra estratégia para superar as leituras desiludidas do Movimento de Pobladores, reconhecendo que as organizações populares não originaram massas de sujeitos críticos portadores de uma democratização renovadora. Ele enfatizará o caráter acumulativo e demorado da mudança social, incorporando algumas noções bourdieusianas a sua análise. Os atores são lentos e as mudanças reversíveis; aqueles não são corpos facilmente manipuláveis pelos processos sociais. Mais do que "homens novos", estamos frente a "homens lentos", determinados por seu habitus cultural. Uma sociologia da mudança deve incorporar uma dimensão de "continuidade" daquilo que resiste à mudança. A razão prática é estável e, por outro lado, muitas mudanças aparentemente rápidas e profundas carecem de durabilidade. Para o autor, é possível entender melhor os efeitos das mudanças que acontecem no contexto das mobilizações para ação coletiva com o habitus e com uma noção de cultura como possível freio, na medida em que nem sempre são atingidas pela intervenção política. Com isso, se evitariam o determinismo (desiludido) e a leitura de disposição à mudança (romanticismo). A mudança não se expressa de maneira imediata. Agora, embora deslocadas a um lugar secundário da democracia, as organizações do mundo popular não desapareceram. Um ator lento não é um ator inerte.

A década de 1990, do ponto de vista do campo de estudos do Movimento de Pobladores, ante a aparente ausência destes, estimulou a elaboração de revisões históricas da trajetória do movimento. O teólogo Maximiliano Salinas (1996) foi um dos autores 
que propôs uma das mais originais reinterpretações da trajetória dos pobladores, a partir de uma perspectiva religioso-popular. Para ele, os pobladores constituem uma sociedade particularmente religiosa que compreende sua própria história como uma passagem do profano ao sagrado, da morte à vida, do não ser ao ser. A partir dessa perspectiva, a luta dos pobladores adquire uma carga mística e pode ser concebida como uma luta pela preservação da sacralidade popular, na qual defendem seu mundo frente à discriminação econômica, social e cultural. Os pobladores afirmam e defendem seu modo de vida valorando a terra, conquistada com um evento ritual fundador, a tomada de terrenos. A terra é vista como um lugar sagrado, apesar de todas as profanações possíveis. Ela possuiria o peso simbólico da madre-terra como imagem magnânima que remete à origem rural dos pobladores, e que se encarna na figura da Virgem. Valores políticos e míticos se misturam nesta trajetória:

Os pobladores formam um mundo próprio composto de crenças, de costumes sociais e religiosos, de 'misturas' impraticáveis pela cultura dominante. Suas convicções religiosas de origem rural a respeito da Virgem, símbolo da 'Mãe Terra', foram colocados em relação com a adesão política ao Partido Comunista chileno, formando assim uma cosmogonia popular comum. Em 1965, o XIII Congresso deste partido reconheceu que os pobladores de Santiago, ao celebrarem as ocupações de terrenos, afirmavam que eles deviam esta vitória ao mesmo tempo ao Partido e à Virgem (SALINAS, 1996, p. 356).

Porém, será a história a disciplina que com maior determinação acolherá o Movimento de Pobladores entre seus tópicos prediletos. O relativo abandono da sociologia e da ciência política, com exceções (DÁVILA, 1994; SEPÚLVEDA, 1998), vai ser compensado por uma série de estudos historiográficos que, frente à ausência do sujeito no presente, buscarão no passado as evidências 
do seu protagonismo. Nesse sentido, a tese de doutorado de Mario Garcés (1999), posteriormente publicada sob o título de Tomando su sitio: el movimento de pobladores de Santiago, 1957-70 (2002), será o texto acadêmico mais importante deste período, exercendo uma influência determinante na formação de novos pesquisadores da área e na conformação de um campo de estudos específico. Para ele, o Movimento de Pobladores ocupa o mesmo patamar de importância que o movimento operário na história social chilena. Eles são os dois grandes atores sociais protagonistas do século XX. Este autor tinha realizado uma importante contribuição à sistematização da memória popular e à promoção da educação popular da direção da ONG Educación y Comunicación (ECO) (GARCÉS, 2010). Mas, já com anterioridade, outros historiadores tinham se dedicado sistematicamente ao estudo deste sujeito social, analisando seja sua trajetória geral (CÁCERES, 1993), seja sua fase de incorporação à vida política nacional (LOYOLA, 2006) ou estudando experiências específicas de organização popular (DE RAMÓN, 1990; FARÍAS, 1992; GÓMEZ LEYTON, 1994; PÉREZ, 1995). Nesse sentido, não se pode deixar de reconhecer a centralidade da figura do historiador Armando de Ramón (2007), quem, no Instituto de História da PUC-Chile, estimulou e orientou intelectualmente a maior parte desta nova geração de historiadores da questão poblacional.

O grande mérito da história foi servir como antídoto às leituras descontinuistas. Porém, embora crescessem as descrições de diferentes episódios da trajetória do Movimento de Pobladores, a discussão conceitual sobre movimentos sociais e sobre o estatuto dos pobladores ficou em dívida. Estes diferentes aportes permitiram superar o "provincianismo histórico" (MILLS, 1995) que apresentavam as leituras conjunturais baseadas, segundo a categoria de Espinoza, no "tempo curto" do Movimento de Pobladores, mas não se responsabilizaram pelos desafios teóricos deixados pelos autores de décadas anteriores. 
Embora a consolidação da história como principal disciplina de estudos dos pobladores nos anos 1990 possa ser considerada uma resposta à saída de cena destes da conjuntura política pós-ditadura, houve alguns acontecimentos que tematizaram esta ausência: a tomada de Peñalolén de 1992 e uma nova tomada realizada na mesma comuna em 1999 (SALAZAR, 2013). Ambas as experiências foram emblemáticas e tiveram marcada presença na mídia nacional, estimularam debates sobre a segregação residencial, sobre o problema habitacional e terminaram por se transformar no marco de inspiração de um "retorno dos pobladores" no Movimento de Pobladores en Lucha (MPL, 2011) como expressão de novas formas de subjetivação político-popular (ANGELCOS, 2010). Porém, sua repercussão na produção de textualidade acadêmica vai ser tardia, ganhando presença só na década seguinte, particularmente quando o conflito assume novos contornos pela proposta de realocação dos pobladores perto de uma Comunidade Ecológica de classe alta, enfrentando duas concepções de cidade e modos de vida (ALVAREZ ROJAS, 2008; CÁCERES, 2003; MARDONES, 2009; ROJAS, 2006). Obviamente este efeito tardio se deve a que a segunda tomada se realiza no final da década de 1990, mas o fato de que a primeira não tenha gerado uma produção mais significativa indica a ausência de uma conjuntura acadêmica favorável à recepção deste acontecimento, desaparecendo o sentido de urgência que outras vezes primou no campo no intuito de registrar e ponderar com rapidez uma determinada irrupção dos pobladores. Contudo, a realização dessas tomadas desmentiu a supostamente definitiva desaparição do Movimento de Pobladores, apesar de sua perda de protagonismo na década.

\section{Do movimento favelado à violência urbana}

No caso do Rio de Janeiro, as favelas não saíram da agenda de pesquisa das ciências sociais durante os anos 1990. Pelo con- 
trário, e tal como mostra a pesquisa de Lícia Valladares e Lidia Medeiros (2003), na qual fizeram uma quantificação analítica de todas as publicações sobre favelas cariocas entre 1906-2000, nesta década se produz uma explosão bibliográfica do tópico. Porém, a favela será protagonista nas ciências sociais não como um lócus de um potencial movimento social, e sim como espaço de intervenção pública (Programa Favela-Bairro) e como principal cenário da violência urbana. Nesse contexto, a ideia de uma "cidade partida" (VENTURA, 1995), sustentada na divisão favela-asfalto, ganhará força explicativa para compreender as dinâmicas urbanas cariocas (CARVALHO, 1993).

As favelas cariocas voltam a ser tema de reflexão sociológica nos anos 1990 na medida em que expressam fenômenos novos, para além da mera 'pobreza' em termos de renda. Sua nova dinâmica aponta para uma sociedade 'fraturada', na qual as leis universais não são efetivamente para todos e a identidade do pobre enquanto 'trabalhador' confunde-se com a do 'bandido'. Nesse contexto a autoridade do crime organizado ganha espaço e legitimidade nas favelas, ao mesmo tempo em que decresce a experiência histórica de luta das associações de moradores e seus ideais políticos. As políticas do Estado para as favelas, voltadas quase que exclusivamente para a repressão e controle do narcotráfico parecem conduzir a um obscurecimento das verdadeiras questões subjacentes à nova dinâmica social das favelas: as da exclusão social moderna e da globalização e suas consequências sociais e políticas (FAUSTO NETO, 1995, p. 417).

A emergência da "violência urbana" como um novo entendimento das ameaças à estabilidade das rotinas cotidianas, com novos significados associados ao crime comum e a novas expectativas e temores em torno da atividade policial rotineira (SILVA, 2012 b), configuraram uma força de gravidade ineludível para as 
ciências sociais, na medida em que ganhou centralidade nas preocupações da sociedade carioca (PAIXÃO, 1990). A consolidação de gangues de traficantes de drogas pesadas, a utilização das favelas como centros de operações dessa atividade e como espaços de disputa entre traficantes, segundo Machado, configuraram um cenário paradoxal, pois, se por um lado, com o início da transição democrática, se reduziram os níveis de violência política como nunca antes na história brasileira, por outro, ocorreu uma escalada da violência na vida diária, que desafiava o processo de democratização e punha o controle social rotineiro no centro da agenda pública.

Já na década de 1980, pesquisas que tinham por objetivo a compreensão das organizações populares ou os significados da pobreza, comprovavam que esse exercício não se podia realizar sem, ao mesmo tempo, incorporar à análise a violência, seja do tráfico armado, seja da polícia, sobre a população favelada (ZALUAR, 1985). Não deixa de ser sintomático que numa das suas análises críticas sobre movimentos sociais no grupo de trabalho da ANPOCS consagrado a este tópico, Machado da Silva (1990, p. 18) tenha afirmado que "seria possível dizer que a violência urbana corresponde, para o campo temático dos movimentos sociais, ao 'outro lado da Lua' - aquele que não pode ser visto, mas existe e é parte do que se vê".

Seja para estudar os processos de urbanização em curso nas favelas (BASTOS e GOMES, 1993) ou para analisar as dinâmicas de lazer (DECCACHE-MAIA, 1999) os pesquisadores se encontrarão com a robusta presença da violência urbana e do tráfico de drogas como um poder paralelo na favela (LEEDS, 1998). Será preciso, portanto, compreender como o crime atinge as dinâmicas da favela, assim como a cultura da violência e as consequências da presença do tráfico armado para a organização social (ZALUAR, 1990, 1998). A violência urbana nas favelas ganha autonomia como campo de estudos e começa a ser compreendida como dota- 
da de uma lógica própria com independência de outros problemas sociais ou como uma forma de sociabilidade específica (SILVA, 1999).

"Pasárgada", nome com o qual Boaventura Santos (1989) batizou a favela na qual realizou o campo de sua tese de doutorado numa alusão utopista a um poema de Manuel Bandeira, deixava de ser um lugar quase mítico, onde as classes oprimidas criavam um direito "informal" como estratégia de sobrevivência perante a legalidade formal hostil através das Associações de Moradores. Agora, passa a ser o lócus de uma judicialidade fundamentada na violência exercida pelo crime organizado do tráfico de drogas, acentuando os processos de atomização social das favelas: "Pasárgada é mais o fruto do imaginário sobre a América Latina construído durante a década de sessenta nos países centrais, do que a situação típica das nossas favelas, que se caracterizam não por laços comunitários, mas pela atomização que reflecte a lógica de cada ator normativo" (JUNQUEIRA e RODRIGUES, 1992, p. 16).

Este pessimismo acadêmico terá sustento no fato de que a emergência da violência urbana deixou a população favelada entre o fogo cruzado de traficantes e policiais, transformando-se no principal obstáculo para a organização popular. Segundo diferentes depoimentos de militantes de favelas (PANDOLFI e GRYNSZPAN, 2003), as associações de moradores sofreram intervenções, em muitos casos, de traficantes, designando chapas favoráveis aos seus interesses, e até algumas lideranças foram executadas por traficantes ou policiais sob a acusação de colaboração com uns ou com outros; as facçôes do tráfico impediram a livre circulação entre favelas, assim como limitaram a liberdade de expressão dentro das comunidades. Ante este cenário que dificultava as possibilidades de representação das favelas, a ausência de antigos aliados (Igreja) e frente ao esvaziamento da base social e legitimidade das Associações de Moradores (LEITE, 2008), muitos militantes tiveram que buscar novas formas de participação. Nesse momento, a figura das ONGs será funda- 
mental para oferecer a esses militantes um espaço de participação e práxis política. As ONGs permitiram que muitos militantes não abandonassem o território e continuassem o disputando, através de uma reinvenção do papel da liderança comunitária, mas restringindo sua ação a um âmbito mais restrito e sem vocação de representatividade.

A reinvenção dos militantes de favelas e a aparição de novas organizações de familiares de vítimas da violência urbana são indícios de que a organicidade favelada, mesmo muito golpeada, não desapareceu nesta década. Aliás, a relação entre movimentos sociais e institucionalidade mostrará que, apesar de tudo, os "novos" atores da década de 1980 deixaram sua marca na jovem democracia brasileira. Segundo Ana Amélia da Silva (1994), os movimentos sociais fizeram uma importante contribuição para a formação de uma nova contratualidade urbana, baseada numa política habitacional que privilegiava a população de baixa renda, enunciando novos direitos e participando na gestão da coisa pública (Câmaras Setoriais, Políticas Públicas Participativas etc.) para além dos conflitos ligados ao trabalho. Os movimentos sociais, em geral, conseguiram institucionalizar a representação dos seus interesses, assim como participar em diferentes canais de negociação. Mas, mesmo tendo deixado sua marca em novas políticas urbanas, no Rio de Janeiro se experimentará um ocaso da principal instância de organização das favelas, as Associações de Moradores. Porém, isso não será sinônimo do fim das organizações com base territorial nas favelas.

A favela, apesar da constante atualização do mito das "classes perigosas", das tentativas de remoção (MAGALHÃES, 2013) e das mais variadas estigmatizações, conseguiu se afirmar no espaço urbano carioca como uma fonte enormemente criativa de expressões culturais e formas de organização (CECCHETTO, 1998; OLIVEIRA e MARCIER, 1998; SANTOS, 1998a). Ao avaliar o século de existência de favelas no Rio de Janeiro, Alba Zaluar e 
Marcos Alvito chegaram à conclusão de que "a favela venceu", mas foi um triunfo precário e constantemente ameaçado:

Não se pode deixar de sublinhar também a capacidade de luta dos favelados na defesa do seu local e estilo de moradia. Após 100 anos de luta, empregando diferentes formas de organização e demanda política, inclusive o carnaval, a favela venceu. Há menos de duas décadas, mudou a legislação, e hoje a favela é feita de habitações de alvenaria [...]. Ninguém fala mais de remoção. Mais recentemente, os projetos de urbanização e saneamento, fruto de pequenas vitórias acumuladas do movimento de favelados, fazem surgir ruas e praças... [Porém] hoje a favela enfrenta novos e terríveis problemas, em face do terror imposto tanto pela polícia, na repressão ao tráfico, quanto pelos próprios traficantes, cada vez mais afastados da população local. Além disso, novos conflitos surgiram e ameaçam aquilo que fez da favela um espaço propício à organização e à criação cultural, livre dos constrangimentos da crença incontestada, do maniqueísmo e da intolerância religiosos. Irá a favela desparecer? (ZALUAR e ALVITO, 1998, p. 21).

A favela venceu, mas o que aconteceu com os favelados e suas organizações? Segundo Machado (2002), a vitória da favela ocorreu à custa da constituição de uma categoria social subalterna que não mudou sua posição nem na sociabilidade urbana, nem na estratificação, assim como não mudou seu papel como força social. Sua expressão política se deu sob um "controle negociado", os agentes externos (Estado, classes dominantes) desistiram da imposição de uma solução unilateral de cima para baixo e os favelados e suas associaçôes utilizaram cada fissura política em proveito dos seus interesses. Nesse percurso, os favelados conseguiram, com muitas dificuldades, se constituir como um ator político, muito mais modestamente do que as ciências sociais esperavam, mas deixando sua marca na vida urbana carioca. 